\title{
O processo de construção de mapas de risco em um hospital público
}

\author{
The process of building risk maps \\ in a public hospital
}

Yara Hahr Marques Hökerberg 1

Maria Angélica Borges dos Santos 2

Sonia Regina Lambert Passos 1

Brani Rozemberg 1

Paulo Marcelo Tenório Cotias 1

Luci Alves 1

Ubirajara Aloízio de Oliveira Mattos 3

\footnotetext{
1 Departamento de Epidemiologia e

Antropologia, Instituto

de Pesquisa Clínica

Evandro Chagas, Fiocruz.

Av. Brasil 4365,

Manguinhos, 21045-900,

Rio de Janeiro RJ.

yarahahr@ipec.fiocruz.br

2 Núcleo de Tecnologia

e Logística em Saúde,

Escola de Governo em

Saúde, ENSP, Fiocruz.

3 Departamento de

Engenharia Sanitária e

Meio Ambiente, Faculdade

de Engenharia, Uerj.
}

Abstract The paper presents a discussion about the experience of building a risk map by workers in a public hospital, in Rio de Janeiro city, resting on concepts of occupational health surveillance, total quality and biosafety. It goes from the first step to persuade the workers and managers, to identify the potential sources of risk in the work environment, the elaboration of the map, until the discussion about the preventive measures and the presentation of the results by the workers at a scientific meeting in the hospital. The elaboration of the risk map acted as a learning opportunity to socialize concepts in the work health area, to integrate workers, to systematize the work process and to discuss work organization, having practical consequences which have furthered changes in the working environment.

Key words Risk map, Public health surveillance, Health services, Occupational health
Resumo O artigo apresenta uma reflexão sobre a experiência de construção coletiva do mapa de risco em um hospital público, no município do Rio de Janeiro, fundamentada nos conceitos de biossegurança, qualidade total e vigilância em saúde do trabalhador. Partiu da etapa de sensibilização dos trabalhadores e gestores do hospital, da identificação dos riscos, da elaboração do mapa, até a discussão sobre as medidas preventivas e a apresentação dos resultados pelos trabalhadores em centro de estudos. A elaboração do mapa de risco serviu como um processo educativo, que possibilitou socializar conceitos da área de saúde do trabalhador, integrar os trabalhadores, sistematizar o processo de trabalho e refletir sobre a forma de organização do trabalho, gerando desdobramentos práticos sob o ponto de vista da intervenção no ambiente de trabalho.

Palavras-chave Mapa de risco, Vigilância em saúde pública, Serviços de saúde, Saúde ocupacional 


\section{Introdução}

As avaliações de risco constituem um conjunto de procedimentos com o objetivo de estimar o potencial de danos à saúde ocasionados pela exposição de indivíduos a agentes ambientais. Tais avaliações servem de subsídio para o controle e a prevenção dessa exposição. Nos ambientes de trabalho, esses agentes podem estar relacionados a processos de produção, produtos e resíduos ${ }^{1}$.

A Norma Regulamentadora NR-9 estabeleceu a obrigatoriedade de identificar os riscos à saúde humana no ambiente de trabalho2, 3 atribuindo às Comissões Internas de Prevenção de Acidentes (CIPA) a responsabilidade pela elaboração de mapas de riscos ambientais. Esse arranjo normativo é considerado por alguns autores uma tentativa de garantir o controle social e a participação do trabalhador na definição de suas condições e processos de trabalho ${ }^{4,5}$.

Tradicionalmente, entretanto, as avaliações de risco são realizadas por especialistas - que aplicam métodos científicos cada vez mais sofisticados para identificar e mensurar quantitativamente os riscos 6 - ou são baseados em instrumentos pré-definidos por comissões de biossegurança ou de qualidade para avaliar os riscos e a conformidade a práticas de segurança 7,8 . Essas abordagens valorizam a adesão a padrões previamente estabelecidos e a modelagem de atitudes e comportamentos dos trabalhadores (uso de equipamento de proteção individual, adesão a boas práticas e capacitação de recursos humanos) e dos ambientes (otimização de infra-estrutura). O objetivo explícito é garantir a observância de padrões de segurança estabelecidos por especialistas, que dominam um saber técnico.

Outra abordagem à avaliação de riscos ambientais, à qual se filiam a metodologia de mapa de risco e o diagnóstico rápido participativo $^{9}$, prioriza a identificação dos riscos pelos trabalhadores, que implica a discussão coletiva sobre as fontes dos riscos, o ambiente de trabalho e as estratégias preventivas para reduzir os riscos identificados.

$\mathrm{Na}$ área de saúde, o controle dos riscos ambientais apresenta intersecções com três áreas: a biossegurança, a saúde do trabalhador e, mais recentemente, a garantia de qualidade em estabelecimentos de saúde.

A biossegurança surgiu a partir de recomendações preventivas, prioritariamente para riscos biológicos, formuladas pela Organização
Mundial de Saúde para controle do ambiente e do processo de trabalho de laboratórios de saúde pública. Posteriormente, incluiu também riscos físicos, químicos e ergonômicos associados às atividades desenvolvidas em qualquer ambiente de atenção à saúde, aproximando-se, em seu escopo, dos programas de qualidade em estabelecimentos de saúde e da saúde do trabalhador10. Não há pressuposto sobre a participação dos trabalhadores na formulação de estratégias de biossegurança, apenas na observância das regras e critérios técnicos.

A partir da Lei Orgânica da Saúde11, a área de saúde do trabalhador aproximou-se da vigilância em saúde do trabalhador. Suas atribuições passaram a incluir a intervenção sobre os ambientes de trabalho, com a promoção de mudanças nas condições e nos processos, a fim de melhorar o quadro de saúde da população trabalhadora. A intervenção, que parte da delimitação de territórios de observação/intervenção e da incorporação do conceito de risco, extrapola o uso de conhecimentos e tecnologias médico-sanitárias e inclui estratégias de comunicação social para estimular a mobilização e a organização dos trabalhadores para a promoção e a defesa das condições de vida e saúde12. Embora possa haver discordâncias quanto à possibilidade de expressão do trabalhador nas estratégias de vigilância em saúde13, o ponto de partida pretende ser a expansão da capacidade de intervenção do trabalhador 14 .

Os programas de qualidade total 15 em serviços de saúde visam promover a qualidade dos ambientes, o controle dos riscos, a observância a padrões de conformidade na perspectiva de melhoria do desempenho da organização, com foco na segurança do paciente, considerando secundariamente a dos profissionais de saúde16, 17. O trabalhador participa propondo mudanças que contribuem para a garantia da qualidade do serviço e melhoria do desempenho organizacional.

Portanto, os três campos disciplinares contemplam os conceitos de risco e segurança dos ambientes de trabalho em um sentido amplo, compreendendo as características físicas (infra-estrutura) e as ações humanas (processos) desse ambiente. Servem, porém, a distintos objetivos e conferem sentidos bem diferentes à participação dos trabalhadores.

Este artigo apresenta uma reflexão sobre a aplicação da metodologia de elaboração coletiva do mapa de risco em um hospital público do município do Rio de Janeiro, que realiza ativi- 
dades de assistência, ensino e pesquisa em doenças infecciosas. A elaboração do mapa de risco integrava uma estratégia de construção de uma proposta ampliada de implantação de ações em biossegurança, qualidade e vigilância em saúde do trabalhador.

\section{O mapa de risco no diagnóstico e intervenção sobre ambientes de trabalho}

O mapa de risco é uma metodologia descritiva e qualitativa de investigação territorial de riscos, difundida no Brasil no início da década de 1980. Foi desenvolvida para o estudo das condições de trabalho e incorpora, em sua origem, a dimensão política de ação do trabalhador na defesa de seus direitos embasada no Modelo Operário Italiano. Suas premissas são a valorização da experiência e do conhecimento do trabalhador (o "saber operário"), a não delegação da produção do conhecimento, o levantamento das informações por grupos homogêneos de trabalhadores e a validação consensual das informações destes trabalhadores, a fim de subsidiar as ações de planejamento e controle da saúde nos locais de trabalho ${ }^{18}$. Na qualidade de instrumento da luta operária pelo controle sobre as condições de trabalho, subentende a aposta na força coletiva de trabalhadores conscientes para gerar as mudanças pretendidas.

As limitações apontadas para o mapa de risco questionam as premissas da metodologia: o saber operário e a possibilidade de intervenção dos trabalhadores organizados sobre suas condições e seu ambiente de trabalho. Zocchio ${ }^{19}$ argumenta que o "saber operário" não pode sobrepujar o "saber técnico" e Sato20 indaga sobre a possibilidade de construção de um "saber operário” centrada em uma lógica própria, como categoria distinta do "saber científico". Laurell \& Noriega ${ }^{21}$ sustentam que o conhecimento particular baseado na experiência não permite generalização e teorização sobre as condições de trabalho.

No contexto de estabelecimentos de saúde, destaca-se, porém, uma peculiaridade. As categorias médicas que estruturam a classificação dos riscos e cujo uso, em princípio, constitui uma contradição para um método que se pretende fundamentado no saber operário ${ }^{20}$, podem estar relativamente "naturalizadas" entre profissionais de saúde, não sendo possível precisar até que ponto já não são constitutivas de suas representações.
Uma outra limitação da metodologia reside na dificuldade de avançar as discussões sobre relações de trabalho (hierárquicas e de vínculo empregatício), que, embora estejam na base das condições de trabalho, não são explicitamente contempladas nas classificações de risco da NR-5 ou da metodologia original italiana. A proposta italiana categorizava os riscos em quatro grupos: 1) fatores presentes no trabalho e nos locais de habitação (luz, temperatura, ventilação e umidade); 2) fatores característicos dos ambientes de trabalho (poeiras, gases, vapores e fumaças); 3 ) fatores que provocam desgaste físico e mental; 4) condições de trabalho que geram estresse e a organização do trabalho ${ }^{18}$. As relações de trabalho não estão claramente enunciadas em nenhuma dessas categorias.

\section{O processo de elaboração do mapa de risco}

A iniciativa de realizar um mapeamento de riscos no Hospital em estudo foi desencadeada por um processo de Acreditação Hospitalar desenvolvido na instituição, cujo primeiro relatório recomendou a realização de um levantamento de riscos ambientais. A medida inscrevia-se dentro de uma tradição institucional de preocupação com biossegurança 10 e configurou-se, ainda, como uma etapa inicial de implantação de um Programa de Vigilância em Saúde do Trabalhador.

A opção pelo mapa de risco foi feita em função: 1) da base legal para uso do mapa de risco como método para a identificação dos riscos; 2) da aparente simplicidade do método; 3 ) da possibilidade de envolvimento ativo dos trabalhadores.

A elaboração do mapa de risco foi precedida de uma etapa de sensibilização dos dirigentes e chefes de serviços para a relevância da iniciativa, seguida de uma visita exploratória realizada pelos autores, para a seleção das áreas a serem analisadas.

A seleção dos ambientes a serem priorizados levou em consideração o tipo principal de atividade desenvolvida no setor, o volume de trabalho (traduzido pela freqüência de realização do procedimento e/ou de utilização dos espaços físicos) e a gravidade dos riscos envolvidos no procedimento. Foram selecionados: no Ambulatório, o procedimento de biópsia na sala de procedimentos; na Internação, as enfermarias de isolamento respiratório; no Hospi- 
tal-Dia, o salão de atendimento, onde são aplicados medicamentos e realizados procedimentos como punção venosa e punção lombar; na Anatomia Patológica, as técnicas de confecção da hematoxilina-eosina e de coloração especial de Grocott e o procedimento de necropsia; na Bacteriologia, o exame de escarro, que incluiu bacterioscopia, cultura e antibiograma; na Radiologia, a realização de radiografias; e na sala de coleta do Laboratório, todos os procedimentos rotineiramente realizados.

Em dois locais a demanda foi espontânea e específica: o Serviço de Bacteriologia, devido a reclamações sobre o ambiente de trabalho e o Serviço de Radiologia, por causa do temor relacionado às radiações ionizantes. Houve, também, necessidade de consultas a Comissão Nacional de Energia Nuclear (CNEN) e a manuais sobre substâncias químicas.

Em seguida, foi realizada a oficina de capacitação na metodologia de mapa de risco, da qual participaram vinte trabalhadores. O grupo envolvido compreendeu trabalhadores encaminhados pelas chefias dos setores e abrangeu várias categorias profissionais, do nível fundamental até superior. Em sua maioria, os trabalhadores envolvidos não ocupavam cargos de chefia, visto que poucos foram os chefes que se interessaram em participar.

As oficinas de treinamento consistiram de cinco encontros semanais, conduzidos por um especialista em mapa de risco (UAOM). Duas das autoras (YHH e LA) foram alunas dessa turma e participaram da construção do mapa em diferentes grupos de trabalho. Inicialmente, foram apresentados conceitos básicos sobre saúde do trabalhador, acidente de trabalho, a notificação dos acidentes de trabalho, a importância da implantação de programas preventivos integrados à área de saúde do trabalhador, como o Programa de Controle Médico e Saúde Ocupacional (PCMSO), o Programa de Prevenção aos Riscos Ambientais (PPRA) e o de Proteção contra Incêndio, e o método a ser empregado para mapear os riscos. A coleta de dados foi feita por grupos de quatro trabalhadores, nos quais pelo menos um integrante atuava no setor analisado ficando, em geral, responsável por apresentar aos demais o processo de trabalho.

O método utilizado implicou a análise dos processos, condições, da forma de organização e das cargas de trabalho, dos materiais empregados e do uso do tempo (jornadas, ritmos, e pausas de trabalho) em vários setores do Hospital. O roteiro do mapa de risco compreendeu a reconstrução e a análise do processo de trabalho, o que incluiu informações a respeito de equipamentos, instalações, materiais, produtos, fluxos, resíduos, turnos de trabalho e atividades dos trabalhadores. Seguiu-se a representação gráfica dos riscos ambientais utilizandose círculos de tamanhos proporcionais à gravidade - grande, médio e pequeno18, 22, segundo a classificação de riscos contida na NR-5: físicos (verde), químicos (vermelho), biológicos (caramelo), ergonômicos (amarelo) e de acidentes (preto).

A etapa seguinte foi a de discussão coletiva das medidas preventivas para as situações de risco detectadas, que incluiu as estratégias de encaminhamento e solução dos problemas ${ }^{23}$. A última etapa consistiu na elaboração de um relatório final por grupo, disponibilizado aos chefes de serviço e à direção geral, após apresentação em Centro de Estudos para a população trabalhadora do Hospital.

Os relatórios e os mapas de risco confeccionados para cada setor, acrescidos da observação direta durante a participação dos autores nas oficinas, constituem a base para a descrição dos resultados. Uma pesquisa bibliográfica posterior e abrangente nas bases Lilacs, Scielo e Medline, utilizando-se os termos "mapa de risco", "risco", "biossegurança” "ambiente" e "hospital”, para o período 1966 até 2005, subsidiou a discussão e as reflexões aqui apresentadas.

\section{Resultados}

A elaboração prática do mapa, iniciada pela discussão sobre os processos de trabalho, provocou muitas reflexões e críticas, gerando também, em alguns momentos, frustrações, posturas de defesa, revolta e resistência.

Na maioria dos setores, não havia registros sobre os materiais utilizados, o processo de trabalho ou os resíduos produzidos. A demanda de registros pelos grupos modificou a organização do trabalho, pois uma vez constatada a inexistência de registros no setor, eles eram organizados pelos componentes do grupo a partir de coleta de dados com os trabalhadores. Este ir-e-vir das oficinas aos setores de trabalho provocou modificações e questionamentos sobre o ambiente de trabalho que se difundiram, em grau maior ou menor, por todo o Hospital.

Chamaram atenção os riscos químicos e ergonômicos apontados pelos trabalhadores, expressos na precária infra-estrutura física e no 
acondicionamento e manejo inadequado das substâncias químicas. Em alguns casos, foram evidenciados verdadeiros "eventos-sentinela" para a área de biossegurança, como trabalhadores fumando em ambientes repletos de substâncias químicas, superlotação de corredores com móveis e geladeiras que armazenam culturas de material biológico e extintores de incêndio em locais inadequados e mal sinalizados.

\section{Diagnósticos relacionados aos processos, insumos e produtos do trabalho}

As principais fontes de exposição a riscos biológicos estavam relacionadas ao contato com sangue e derivados, excreções e secreções, líquidos corporais, fragmentos de tecidos e cadáveres de pacientes portadores de doenças infecciosas durante a realização de procedimentos como coleta de exames, punção venosa periférica, nebulização para escarro induzido, exame de liquor, biópsia, processamento dos exames laboratoriais, administração de medicamentos, higiene de pacientes, do instrumental e do ambiente. A aerossolização de agentes patogênicos de transmissão respiratória, como o bacilo da tuberculose e alguns fungos, foi atribuída ao sistema de ventilação/exaustão inadequado dos ambientes de trabalho. Os setores que relatavam riscos biológicos foram o setor de coleta, $\mathrm{o}$ ambulatório, a internação e o Hospital-Dia.

As exposições a riscos químicos foram relacionadas às soluções utilizadas nas técnicas de hematoxilina-eosina e Grocott, na Anatomia Patológica; às técnicas de detecção de bacilo álcool-ácido resistentes, na Bacteriologia; aos reveladores e fixadores, na Radiologia. Foi atribuída potencial fonte de risco químico aos medicamentos utilizados no Hospital-Dia e na Internação; ao oxigênio e nitrogênio do setor de Internação e aos detergentes e desinfetantes usados na limpeza de todos os ambientes.

Os riscos físicos citados foram: 1) ruídos provenientes da sala de recepção de pacientes, dos alarmes de equipamentos sem manutenção preventiva, campainhas, portas, rodas dos carrinhos de transporte; e 2) radiação proveniente dos equipamentos de raios $\mathrm{X}$, da manipulação de carbono 14 na Bacteriologia, das lâmpadas ultravioleta nas enfermarias de isolamento respiratório e na sala de necropsia.

A principal queixa ergonômica apresentada foi o esforço físico repetitivo. Os representantes das equipes de enfermagem relacionaram esta queixa ao transporte de pacientes portadores de deficiências físicas e ao auxílio na realização de exames clínicos complementares no Ambulatório, Internação e Hospital-Dia. Na Anatomia Patológica e na Radiologia, o risco estava relacionado à manipulação de grandes vasilhames contendo soluções químicas.

O risco de acidentes decorrentes da utilização de equipamentos perfurocortantes (agulhas, lâminas de bisturi, vidrarias, micrótomo) foi sinalizado em todos os setores, exceto na Radiologia. O potencial de estarem associados à iluminação e estrutura física inadequadas também foi registrado. Fatores como o armazenamento inapropriado de substâncias químicas, a existência de instalações elétricas e de gás obsoletas, mal sinalizadas e sem manutenção preventiva, aliados à inexistência de um programa de treinamento de combate a incêndios, foram apontados como contribuintes potenciais para a ocorrência de acidentes com material perfurocortante, queimaduras, choques elétricos, incêndios e explosões, especialmente nos setores de Internação, Anatomia Patológica e Bacteriologia.

Durante a reconstrução do processo de trabalho, ficaram evidentes as restrições de espaço físico em todos os setores, sendo que, em alguns deles as modificações são difíceis devido ao tombamento do prédio pelo patrimônio histórico. Outra questão apontada foi o fato de alguns processos de trabalho requererem a travessia entre prédios, que são entrecortados por vias com acesso a veículos automotores.

O quadro 1 sintetiza potenciais doenças e síndromes relacionadas pelos trabalhadores aos cinco grupos de risco identificados nos setores mapeados.

\section{Diagnósticos ligados às condições \\ e às relações de trabalho}

Uma das principais questões levantadas referiu-se à escassez de recursos humanos e aos diferentes vínculos empregatícios existentes na instituição, que abrangem servidores públicos, prestadores de serviço, funcionários de cooperativas, bolsistas, estagiários remunerados e não remunerados. Os servidores públicos, com vínculos estáveis, corresponderam a apenas cerca de um quinto do total da população trabalhadora do Hospital. A grande quantidade de trabalhadores sem vínculo empregatício torna a percepção de risco variável e, possivelmente, minimizada pelo temor de desemprego provocado por não terem estabilidade no emprego ou direitos trabalhistas. 


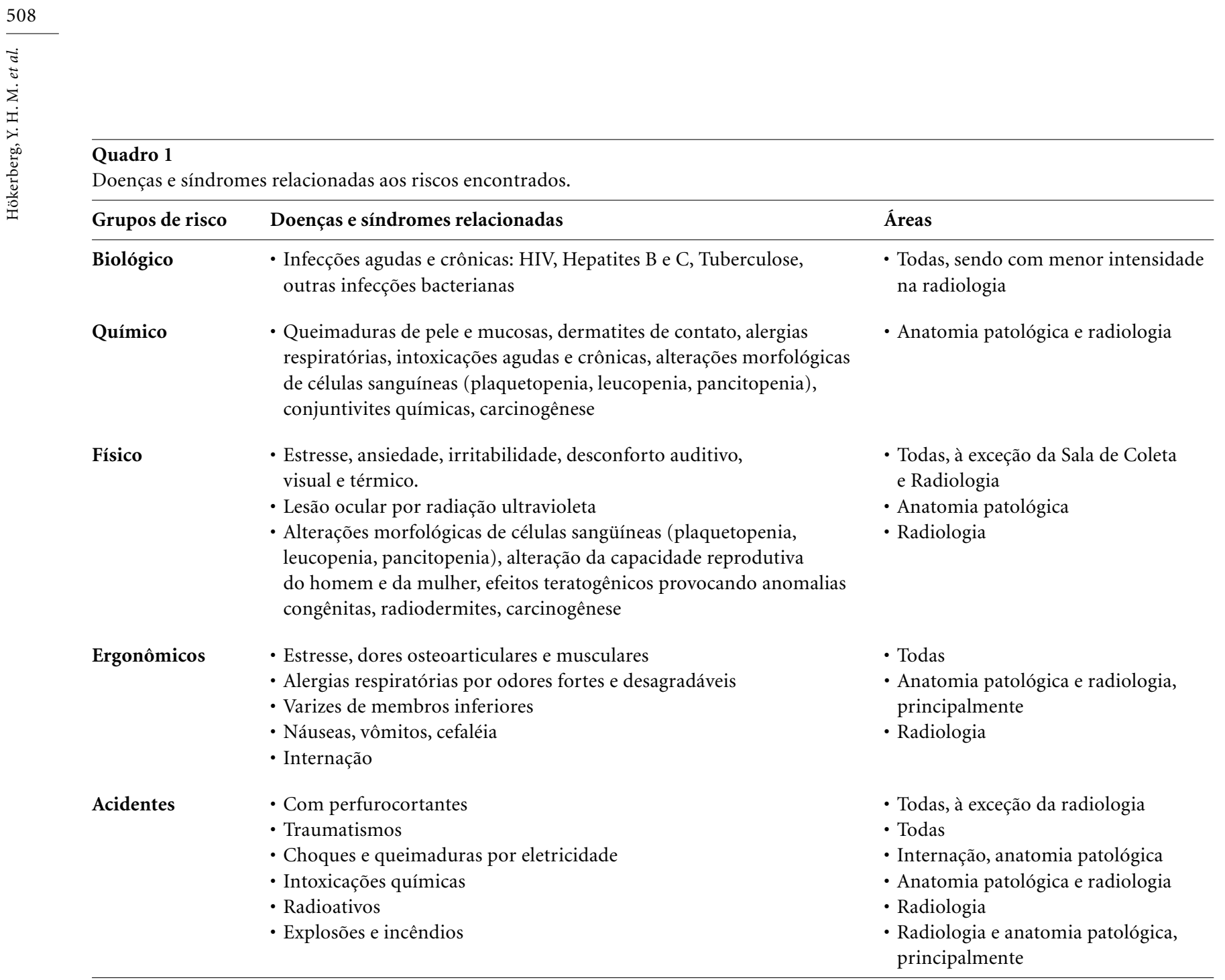

\section{Recomendações e desdobramentos}

As medidas preventivas apontadas foram precedidas de uma discussão das Normas Regulamentadoras do Ministério do Trabalho e Emprego considerando-se a viabilidade e o âmbito da ação preventiva (de nível individual, particular ou geral)23.

Entre as propostas centradas primordialmente na adequação dos ambientes e processos de trabalho, a principal medida preventiva apontada foi a ampliação da área física da Unidade ou dos ambientes de trabalho. Foi sugerida a criação de algumas novas áreas para expurgo, lavagem e esterilização de material, armazenamento de resíduos e para o tratamento de esgoto. Identificou-se a necessidade de melhoria das áreas de circulação e os fluxos do processo de trabalho, além da correta sinalização dos riscos, bem como da construção de refeitórios e de locais para o repouso dos traba- lhadores. A discussão sobre os obstáculos relativos à adequação de espaço físico no prédio tombado pelo Patrimônio Histórico, onde estão situadas a Anatomia Patológica e a Internação, gerou alternativas de curto e médio prazo e forneceram subsídios para antiga reivindicação de construção de um novo prédio defendida pela Direção do Hospital.

Quanto à organização do ambiente de trabalho, os trabalhadores recomendaram a rotulagem e o armazenamento adequados de produtos químicos, com a elaboração de tabelas e fichas com orientações sucintas sobre incompatibilidade e manuseio seguro de substâncias potencialmente tóxicas e sobre procedimentos a serem adotados em caso de acidentes e/ou intoxicações. Além disso, sugeriu-se a elaboração e a divulgação de normas para o transporte de material biológico e substâncias químicas.

Foi apontada a necessidade de um programa de manutenção preventiva regular dos equi- 
pamentos. Para as cabines de fluxo laminar, foram propostos a limpeza e trocas periódicas de filtros e o redirecionamento da exaustão externa das cabines para uma altura acima do telhado, minimizando o contato com áreas de circulação de pessoas. Foi sugerida uma nova inspeção nos ambientes para aprovar e certificar os dispositivos de proteção, como é o caso das blindagens com barita na Radiologia e das cabines de fluxo laminar.

Medidas de proteção coletiva buscam evitar que a responsabilidade sobre um acidente recaia exclusivamente no uso inadequado de determinado equipamento de proteção individual pelo trabalhador. Em 2003, foram instalados equipamentos de proteção coletiva, como filtros HEPA com pressão negativa, nos quartos de isolamento respiratório da Internação e no laboratório de tuberculose da Bacteriologia. Outra medida proposta foi a implantação e ampla divulgação de uma política de gerenciamento de resíduos, que incluiria a construção de um abrigo de resíduos, a sinalização e o transporte adequado, visando ao manejo correto de materiais perigosos e a qualificação de recursos humanos.

Os episódios mais significativos de mudanças vinculadas ao processo de elaboração do mapa de risco foram: 1) a reforma do laboratório de Bacteriologia; 2) a remoção de duas poltronas de atendimento do Hospital-Dia, que obstruíam a circulação das enfermeiras, para a abertura de espaço necessário à instalação de um filtro HEPA. A mudança teve como objetivo evitar acidentes e melhorar a qualidade do ar, especialmente no que diz respeito às doenças de transmissão respiratória. Para que esta medida, que culminava em redução de leitos e produtividade, fosse implementada foi necessária uma apresentação em Centro de Estudos, que envolveu vários trabalhadores e gestores em acalorado debate; 3 ) subsidiar a decisão da Anatomia Patológica de não realizar procedimentos de necropsia, uma vez que não havia sistema de ventilação/exaustão implantado e o ar-condicionado central era compartilhado com setores administrativos. Os relatórios de mapeamento de risco fundamentaram reiterados memorandos da direção da unidade para o órgão de administração central, que culminaram na realização de um diagnóstico sobre ventilação/exaustão, na adequação do espaço físico e na revisão do sistema de ar-condicionado do andar térreo do prédio; 4) a revisão da disponibilidade de equipamentos de proteção indi- vidual e, quando possível, implementação de equipamentos de proteção coletiva; 5) a sensibilização dos trabalhadores quanto ao cuidado com a própria saúde; 6) a possibilidade de os trabalhadores conhecerem realidades distintas, embora espacialmente próximas (Radiologia, Anatomia Patológica, Farmácia, Zoonoses), e uma maior integração entre os diferentes setores.

Podem ser citados como desdobramentos, ainda, a realização de uma nova oficina no ano seguinte, com uma demanda espontânea muito maior dos trabalhadores, as duas divulgações no Centro de Estudos e o encaminhamento de recomendações para a Comissão Técnica de Biossegurança e para a Presidência da instituição.

\section{Discussão}

A presente experiência de aplicação da metodologia de mapa de risco visava, fundamentalmente, buscar soluções para os problemas encontrados nas áreas de segurança do ambiente hospitalar nos relatórios sobre o diagnóstico dos riscos ambientais e no mapa de risco em sua representação gráfica final. Entretanto, os autores foram confrontados com a centralidade do processo de construção do mapa e o seu potencial de suscitar debate e socializar percepções sobre as várias dimensões do trabalho.

Metodologias participativas de avaliação de riscos trazem à tona diagnósticos que comportam três dimensões: as relacionadas aos ambientes e processos de trabalho (uma dimensão técnica); as referentes às relações de trabalho (uma dimensão política) ${ }^{20}$; e aquelas relacionadas às dimensões subjetivas.

A construção do mapa de risco possibilitou a reflexão sobre o processo de trabalho nos vários setores expostos a diferentes graus de estresse, imprecisão das tarefas e necessidade de decisões rápidas para, ao final, possibilitar a proposta coletiva de medidas preventivas e corretivas $^{24}$. O mapa de risco constituiu-se, portanto, em um referencial "prescrito" não apenas para ser "cumprido conforme o planejado", mas para propiciar uma mudança perceptual sobre os riscos e servir como base para reflexão e construção de novos conhecimentos $25,26$.

$\mathrm{Na}$ experiência apresentada, o mapa de risco permitiu evidenciar fontes de risco químico não rotineiramente presentes na preocupação dos trabalhadores e gestores de hospitais, mas muito comuns na avaliação de ambientes industriais 27 . 
Em alguns casos foram evidenciados riscos antes naturalizados, por estarem imersos nas rotinas de trabalho e que talvez fossem relevados em nome do alto valor social do trabalho em saúde. Ou ainda, pelo contrário, como conseqüência de um amortecimento da percepção do risco ligado à perda de controle sobre as condições de trabalho ${ }^{20}$. Não pudemos aferir em que medida os vínculos precários influenciaram a autonomia do trabalhador para identificar ou sua tendência a naturalizar os riscos. A composição mista dos grupos de mapeamento possibilitou que outros evidenciassem o risco que alguns subestimaram.

A subjetividade dos atores envolvidos na realização do mapa de risco perpassa todas as análises e a confecção dos relatórios, especialmente no momento de atribuir intensidade aos riscos. Um exemplo é o fato de o setor de Coleta não relatar ruídos como fonte de risco físico, ainda que este risco seja nítido e perceptível para quem não trabalha no setor. É plausível que os acidentes com material biológico no setor representem uma questão premente a ponto de obscurecer a percepção de quaisquer outros problemas.

Todos os setores avaliados enfatizaram a ocorrência de acidentes com material perfurocortante e o contato prolongado com material biológico, provavelmente porque os acidentes com material biológico, e os conseqüentes riscos de infecção pelos vírus da hepatite $\mathrm{B}, \mathrm{C}$ e HIV entre profissionais de saúde, são bem conhecidos e divulgados 28,29 . Outras doenças infecciosas - como tuberculose, influenza, varicela-zoster coqueluche e doença meningocócica - também estão associadas ao trabalho em estabelecimentos de saúde.

No contexto da emergência e reemergência de doenças infecciosas, alguns agentes biológicos se manifestam com maior gravidade em profissionais de saúde ${ }^{30}$. Tendo em vista a missão institucional do hospital em estudo, seria esperado que a percepção de risco relacionada a essas doenças emergentes fosse mais evidente.

O destaque conferido às lesões por esforços repetitivos, principalmente na segunda turma de alunos do curso de mapa de risco, também pode estar ligado ao domínio público dessa síndrome, em detrimento de outros riscos menos catalogados e divulgados.

No caso específico do processo de elaboração de mapa de risco em estudo, o uso e a organização do espaço físico emergiram como questões centrais a serem priorizadas para a preven- ção dos acidentes. Não apenas os acidentes e a transmissão de doenças infectocontagiosas, mas também o estresse e as doenças osteoarticulares foram relacionados ao espaço físico, por demandarem maiores esforços dos trabalhadores em ambientes desprovidos de conforto. Outros estudos sobre o trabalho em ambientes de atenção à saúde mostram, no caso dos laboratórios de análises clínicas, a relação entre os tempos permitidos para a conclusão de tarefas e o maior risco de acidentes e, no banco de leite humano, a influência do desgaste emocional das profissionais de enfermagem sobre a morbidade ocupacional 5 .

Estudos recentes têm discutido morbidade referida, jornadas de trabalho, trabalho noturno, estresse e ansiedade, especialmente no grupo de profissionais de enfermagem ${ }^{31}, 32,33$. Portela 34 aponta como principais queixas em profissionais de enfermagem a cefaléia/enxaqueca, varizes de membros inferiores, ansiedade/insônia, alergias respiratórias e morbidade psiquiátrica menor. Entretanto, esses são desfechos cujos "riscos potenciais" são aspectos que o mapa de risco não prevê como sinalizar, representar e interpretar, apesar de externalizados em dimensões de sofrimento físico e psíquico. No trabalho de Silveira 31 , o sofrimento e o adoecimento de profissionais de enfermagem do hospital relacionava-se à organização do processo de trabalho, às relações hierárquicas, aos vínculos de trabalho precários, à falta de clareza sobre as atividades a serem desempenhadas e à desvalorização profissional.

O mapa de risco é criticado por partir de um pressuposto cartesiano de que é possível classificar, quantificar e delimitar fisicamente todos os riscos presentes no ambiente de trabalho e por não contemplar as interações entre riscos, que contribuiriam mais para o risco de acidentes e morbidade do que fatores de risco isolados 5 . No entanto, em nossa experiência, a escassez de recursos humanos e a realização de trabalhos repetitivos (com pipetas, micromanipulações, pesagens, computadores, microscópio) foram citados como fatores que, simultaneamente, contribuíram para o aumento dos riscos à saúde e de acidentes. A citação destas e de outras categorias de risco de forma interativa sugere que a elaboração do mapa tenha permitido aos trabalhadores vislumbrarem a natureza multifatorial do risco.

Por valorizar a percepção dos trabalhadores, ao mesmo tempo em que os sensibilizou para as questões relativas à segurança, qualida- 
de e saúde no ambiente de trabalho, o mapa de risco funcionou como um espaço que possibilitou a socialização e a discussão da forma de organização do trabalho em cada setor, prescritas e reais. Tal como descrito por Neves et al. 25 , que analisaram o setor de manutenção de um hospital universitário, a participação dos trabalhadores contribuiu para a geração de novas regras partilhadas, reconhecendo equívocos no que está definido em termos de organização do trabalho.

O mapa de risco não incorpora as classificações de risco de biossegurança, pois não é um instrumento específico para trabalhadores da saúde. Visando aproveitar o trabalho realizado durante a elaboração do mapa, foi realizado um levantamento posterior sobre os agentes biológicos manipulados em laboratório para classificá-los conforme o risco de biossegurança (nível de biossegurança - NB1, NB2, NB3, NB4).

Em pelo menos dois pontos, o mapa de risco cumpriu as promessas implícitas em sua formulação original ligada ao movimento operário. O primeiro foi no processo educativo de difusão de conceitos da área de saúde do trabalhador, em que as formulações originais do modelo operário italiano destacam o "saber operário", mas reconhecem que o combate à nocividade do ambiente de trabalho exige a socialização do conhecimento técnico nesse campo ${ }^{18}$. O segundo foi na perspectiva de ter, em seus desdobramentos, reforçado a importância da reivindicação coletiva ressaltada pelo Movimento Operário.

\section{Considerações finais}

A metodologia do mapa de risco presta-se à implementação e reforço de medidas de biossegurança, vigilância em saúde do trabalhador e qualidade total, uma vez que cria ou reforça uma consciência do risco que todas essas disciplinas valorizam, e das capacidades individuais e, em alguma medida, coletivas de modificar esses riscos.

Por outro lado, o mapa de risco confere centralidade à participação do trabalhador na elaboração de estratégias para prevenção de riscos ambientais. $\mathrm{O}$ aumento da capacidade crítica e o empowerment do trabalhador, assimilados tanto nas filosofias de qualidade - como ferramenta - quanto na vigilância em saúde - como princípio, não produzem um traba- lhador necessariamente "dócil". Talvez isso explique a baixa adesão das chefias e as dificuldades enfrentadas para implementar medidas às vezes simples sugeridas no processo de construção do mapa de risco.

De um modo geral, as categorias de risco trabalhadas foram as propostas pela NR-5: biológicos, químicos, físicos, ergonômicos e de acidentes. O estresse e as relações de trabalho surgiram nas discussões sobre as estratégias de prevenção de riscos, quando foram descritos os conflitos cotidianos e as barreiras a serem enfrentadas para alcançar as ações pretendidas. Mas, infelizmente, não são registradas de modo adequado nos relatórios e mapas, que ficam restritos aos riscos "visíveis" e normatizados.

Em que medida a forma como foi aplicada a metodologia de mapa de risco em nossa unidade de saúde apenas reforçou um saber técnico ou estranho aos legítimos interesses do trabalhador?

A construção do mapa desencadeou reflexões sobre o papel e a importância dos trabalhadores, o que poderia sustentar a construção coletiva dos objetivos e da missão da instituição, uma diretriz dos programas de qualidade total. Mas, como argumentam os críticos da qualidade, a participação dos trabalhadores nesses programas pode ser simplesmente uma estratégia para aumentar a adesão a práticas de conformidade e o rendimento do trabalhador e servir, principalmente, aos interesses da organização ${ }^{35}$. Por outro lado, a construção do mapa também pode, de fato, induzir no trabalhador uma perspectiva mais crítica e vigilante, como propõe a vigilância em saúde do trabalhador ${ }^{14}$, ou aumentar a consciência de risco, melhorando a efetividade das ações de biossegurança.

Mesmo que a "consciência do risco" não tenha necessariamente poder para determinar mudanças de comportamento, e que os reais sentidos do mapa de risco exijam que se avance além dessa função de conscientização, pode ser reducionista a compreensão de que os meses de vivência deste trabalho se resumiram à confecção de um "instrumento burocrático, que enfeita as paredes dos estabelecimentos e aos quais ninguém presta atenção" 5 .

Em nosso entendimento, o mapa de risco possibilitou o replanejamento do processo de trabalho a partir da experiência cotidiana e coletiva vivenciada no decurso de sua elaboração ${ }^{36}$ e permitiu aos trabalhadores proporem soluções criativas para os problemas detectados 26 . 
De fato, foi bastante restrita a possibilidade de elaborar de forma explícita e consciente os conteúdos mais subjetivos e políticos que afloraram durante o processo de construção do mapa. Mas, não há como ignorar que, ao longo dos anos, houve mudanças nas características da luta do trabalhador, que talvez hoje não seja mais revolucionária, como propunha o modelo operário italiano, mas baseada em negociações cotidianas ${ }^{36}$. Este pode ser um caminho viável para, incrementalmente, promover mudanças.

Alguns dos episódios relatados, porém, sugerem que o processo de elaboração do mapa tenha propiciado vivências como as pretendidas pelo Movimento Operário, ao demonstrar, por exemplo, o peso da reivindicação coletiva na promoção de um número emblemático de mudanças contra as quais as chefias, em princípio, se opunham.

O mais relevante foi a reflexão suscitada nos trabalhadores e a mudança de perspectiva de passivos e reclamantes para atores com capacidade de interferir sobre o ambiente de trabalho. Estas reflexões geraram insights sobre a natureza do trabalho executado, tensões, insatisfações e angústias que corresponderiam a símbolos sem cor, invisíveis aos olhos na linguagem do mapa, mas reconhecidamente essenciais para todos os envolvidos neste percurso. O desafio será sustentar ao longo do tempo, diante da realidade das relações de trabalho no mundo atual, o aprendizado trazido pelo mapa.

\section{Colaboradores}

YHM Hökerberg participou da coleta de dados, das oficinas de trabalho, concepção teórica, levantamento bibliográfico, elaboração e redação final do texto; MAB dos Santos e SRL Passos participaram da concepção teórica, levantamento bibliográfico, redação e revisão do texto; B Rozemberg participou da análise dos dados; PMT Cotias e L Alves participaram das oficinas de trabalho, da coleta e análise dos dados; e UAO Mattos coordenou as oficinas de trabalho, participou da elaboração conceitual, consolidação e análise dos dados.

\section{Referências}

1. Porto MFS, Freitas CM. Análise de riscos tecnológicos ambientais: perspectivas para o campo da saúde do trabalhador. Cad Saúde Pública 1997; 13(Suppl 2):109-18.

2. Portaria no. 3.214. Aprova as Normas Regulamentadoras (NR) do Ministério do Trabalho e Emprego. Diário Oficial da União 1978; 8 jun.

3. Portaria no. 25. Aprova o texto da Norma Regulamentadora no. 9 - Riscos Ambientais do Ministério do Trabalho e Emprego. Diário Oficial da União 1994; 29 dez.

4. Miranda CR, Dias CR. PPRA-PCMSO: auditoria, inspeção do trabalho e controle social. Cad. Saúde Pública 2004; 20(1):224-32.

5. Assunção AA. Uma contribuição ao debate sobre as relações saúde e trabalho. Rev C S Col 2003; 8(4): 1005-18.

6. Freitas CM \& Sá IMB. Por um gerenciamento de riscos integrado e participativo na questão dos agrotóxicos. In: Peres F, Moreira JC, organizadores. É veneno ou é remédio? Agrotóxicos, saúde e ambiente. Rio de Janeiro: Fiocruz; 2003. p. 211-50.

7. Rocha SS, Santos CMDG. Avaliação de riscos das atividades do Laboratório Central de Saúde Pública. Seminário Nacional de Saúde e Ambiente no Processo de Desenvolvimento. Saúde e Ambiente no Processo de Desenvolvimento. Rio de Janeiro: Fiocruz; 2000. p. 183. (Série Fiocruz Eventos Científicos 2). 
8. Cardoso TAO, Rocha SS, Lima e Silva FHA, Ermida AHA. Indicadores de qualidade em biossegurança: avaliação de risco em instituição de ensino e pesquisa na área de saúde pública. Seminário Nacional de Saúde e Ambiente no Processo de Desenvolvimento. Rio de Janeiro: Fiocruz; 2000. p. 184. (Série Fiocruz Eventos Científicos 2).

9. Santos LA, Guimarães KR, Teodoro VA, Bevilacqua PD. Biossegurança em ambiente hospitalar/laboratorial e o uso das técnicas de DRP: experiência no Departamento de Veterinária da Universidade Federal de Viçosa (DVT/UFV). Seminário Nacional de Saúde e Ambiente no Processo de Desenvolvimento. Rio de Janeiro: Fiocruz; 2000. p. 181. (Série Fiocruz Eventos Científicos 2).

10. Minayo MCS, Machado JMH, Matos LBF, Oda LM, Vieira VM, Monteiro TCN. Fiocruz saudável. Uma experiência institucional. Seminário Saúde e Ambiente no Processo de Desenvolvimento. Rio de Janeiro: Fiocruz; 1999. p. 63-76. (Série Fiocruz Eventos Científicos 1)

11. Lei no 8.080. Lei Orgânica da Saúde. In: Santos L, organizador. Coletânea Leis e Julgados de Saúde. Campinas: IDISA; 1990. p. 25-166.

12. Teixeira CF, Paim JS, Vilasbôas AL. SUS, modelos assistenciais e vigilância da saúde. Informe Epidemiológico do SUS 1998; 7:29-34.

13. Lacaz FAC. Saúde dos trabalhadores: cenários e desafios. Cad Saúde Pública 1997; 13(Supl 2):7-19.

14. Machado JMH. Processo de vigilância em saúde do trabalhador. Cad Saúde Pública 1997; 13(Supl 2):3345.

15. Nogueira RP. Perspectivas da qualidade em saúde. Rio de Janeiro: Editora Qualitymark; 1994.

16. Zanon U. Qualidade da assistência médico-hospitalar. Conceito, avaliação e discussão dos indicadores de qualidade. Rio de Janeiro: Editora Médica e Científica Ltda.; 2001.

17. Consórcio Brasileiro de Acreditação. Manual Internacional de Padrões de Acreditação Hospitalar. Rio de Janeiro: UERJ/Cepesc; 2003.

18. Mattos UAO, Freitas NBB. Mapa de risco no Brasil: as limitações da aplicabilidade de um modelo operário. Cad Saúde Pública 1994; 10(2):251-8.

19. Zocchio A. Do cumprimento da legislação ao mapa de riscos ambientais. CIPA 1993; 159:28-9.

20. Sato L. As implicações do conhecimento prático para a vigilância em saúde do trabalhador. Cad Saúde Pública 1996; 12(4):489-495.

21. Laurell AC, Noriega M. Processo de trabalho e saúde - trabalho e desgaste operário. São Paulo: Cebes; Hucitec; 1989.

22. Mattos UAO, Queiroz AR. Mapa de risco. In: Teixeira P, Valle S, organizadores. Biossegurança. Uma abordagem multidisciplinar. Rio de Janeiro: Fiocruz; 2002. p. 111-22.

23. Mattos UAO, Porto MFS. Estratégias de prevenção, gerenciamento de riscos e mudança tecnológica. In: Mendes R, organizador. Patologia do trabalho. 2a ed. atual. e rev. São Paulo: Atheneu; 2003. p. 1721-39.
24. Machado JMH, Correa MV. Reflexões sobre a observação do processo de trabalho: introduzir o conceito de vida no trabalho na análise das relações entre processo de trabalho e saúde. Seminário Saúde e Ambiente no Processo de Desenvolvimento. Rio de Janeiro: Editora Fiocruz; 2000. p. 92-100. (Série Fiocruz. Eventos Científicos 1).

25. Neves MY, Vieira S, Araújo A, Uchôa N. Trabalho e saúde mental: vivência subjetiva dos trabalhadores do Setor da Manutenção do Hospital Universitário/UFPB. In: Silva Filho JF, Jardim S, organizadores. A danação do trabalho. Organização do trabalho e sofrimento psíquico. Belo Horizonte: Te Cora Editora; 1997.p. 147-72.

26. Dejours C. A loucura do trabalho: estudo de psicopatologia do trabalho. São Paulo: Costez-Oboré; 1991.

27. Finkelman J. Chemical Safety and Health in Latin América: an Overview. Sci Total Environ 1996; 188 (Suppl 1):S3-S29.

28. Rapparini C, Cardo DM. Principais doenças diagnosticadas em profissionais de saúde. In: Mastroeni MF, organizador. Biossegurança aplicada a laboratórios e serviços de saúde. São Paulo: Atheneu; 2004. p. 205-18.

29. Yoshida CFT. Hepatite B como doença ocupacional. In: Teixeira P, Valle S, organizadores. Biossegurança. Uma abordagem multidisciplinar. Rio de Janeiro: Fiocruz; 2002. p. 257-72.

30. Ho AS, Sung JJ, Chan-Yeung M. An outbreak of severe acute respiratory syndrome among hospital workers in a community hospital in Hong Kong. Annals of Internal Medicine 2003; 139: 564-7.

31. Silveira GRM. Trabalho e saúde no hospital: o caso das trabalhadoras de enfermagem do Instituto de Pesquisa Clínica Evandro Chagas/Fiocruz (dissertação). Rio de Janeiro: Escola Nacional de Saúde Pública, Fiocruz; 2003.

32. Rotenberg L, Portela LF, Marcondes WB, Moreno C \& Nascimento CP. Gênero e trabalho noturno: sono cotidiano e vivências de quem troca o dia pela noite. Cad Saúde Pública 2001; 17(3):639-49.

33. Braga D. Acidente de trabalho com material biológico em trabalhadores da equipe de enfermagem do Centro de Pesquisas Hospital Evandro Chagas (dissertação). Rio de Janeiro: Escola Nacional de Saúde Pública, Fiocruz; 2000.

34. Portela LF. Morbidade referida e gerenciamento do tempo em profissionais de enfermagem: relações com o horário de trabalho, jornada semanal e trabalho doméstico (dissertação). Rio de Janeiro: Escola Nacional de Saúde Pública, Fiocruz; 2003.

35. Silva RC. Poder invisível, formas de controle e gestão da qualidade total: O caso da siderúrgica rio-grandense. In: Vieira MMF, Carvalho CA, organizadores. Organizações, instituições e poder no Brasil. Rio de Janeiro: Fundação Getúlio Vargas; 2003.

36. Sato L. Prevenção de agravos à saúde do trabalhador: re-planejando o trabalho através das negociações cotidianas. Cad Saúde Pública 2002; 18(5):1147-66.

Artigo apresentado em 18/07/2005

Aprovado em 13/12/2005

Versão final apresentada em 12/01/2006 